Driving Innovation from Within 



\section{KAIHAN KRIPPENDORFF}

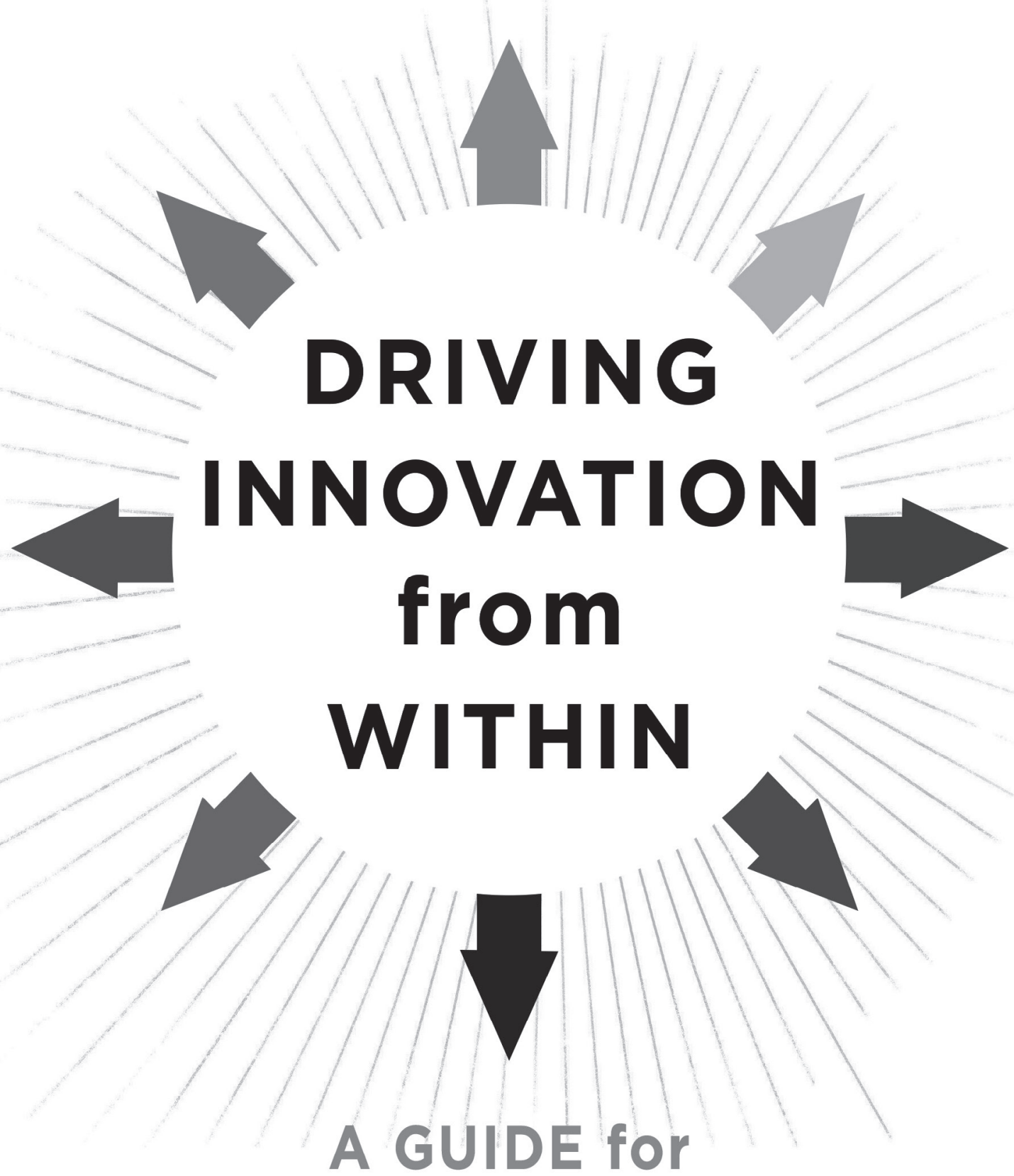

INTERNAL ENTREPRENEURS

\section{Columbia Business School


Columbia University Press

Publishers Since 1893

New York Chichester, West Sussex

cup.columbia.edu

Copyright (C) 2019 Kaihan Krippendorff

All rights reserved

Library of Congress Cataloging-in-Publication Data

Names: Krippendorf, Kaihan, author.

Title: Driving innovation from within : a guide for internal entrepreneurs /

Kaihan Krippendorf.

Description: New York : Columbia University Press, [2019] |

Includes bibliographical references and index.

Identifiers: LCCN 2019021922 (print) | LCCN 2019980593 (e-book) |

ISBN 9780231189521 (hardback) | ISBN 9780231548366 (e-book)

Subjects: LCSH: Intellectual capital-Management. | Creative ability in

business. | New products. | Technological innovations-Management. |

Organizational change.

Classification: LCC HD53 .K74 2019 (print) | LCC HD53 (e-book) |

DDC 658.4/063- dc23

LC record available at https://lccn.loc.gov/2019021922

LC ebook record available at https://lccn.loc.gov/2019980593

Columbia University Press books are printed on permanent and durable acid-free paper.

Printed in the United States of America

Cover design: Noah Arlow 
For Lucas, Kaira, and Makar.

May you do what you love. 
